\title{
Using Compact Discs as a Supplement to an Orientation Program
}

Harrison Greenlaw \& Scott Kaplan

The days of universities and colleges slowly recognizing and implementing changes in recruitment, orientation, and retention strategies are in the past. Technology advances literally daily, and any campus waiting to stay abreast will be left behind. With this in mind, many orientation directors are exploring new ways to communicate efficiently and effectively with entering students. One of the fasting growing concepts is the use of compact discs (CDs) as a means of communication with incoming students. There are, however, questions not yet answered on whether they are cost-effective and as useful as projected.

CDs make use of a popular means of auditory and visual communication. Many college officials consider informational CDs to be a viable means of communication for a number of reasons such as:

(a) CDs are popular with students who have literally grown up with CDs as commonplace tools for them;

(b) Many students have a home, car, or portable CD player for audio listening;

(c) CDs are capable of holding considerable amounts of information on a small disc which is easy to handle and inexpensive to ship;

(d) Mass-produced CDs are quickly produced and relatively inexpensive;

(e) CDs allow orientation staffs and other administrators to be assured of the consistency of information delivered since all students receive identical information;

(f) The CD can be replayed for additional information; and

(g) The CD can be a tool for both the incoming students and their parents

It should be emphasized that CDs cannot replace established orientation programs. On-campus orientation programs offer colleges and universities the opportunity to present additional and more personalized information, and for students to have personal attention. Though CDs cannot answer individual questions, they are nonetheless an excellent way to give pertinent and descriptive information to incoming students or those considering various colleges.

Each campus should determine whether or not a CD could augment an orientation program and whether their constituency is more suited to receive a CD for audio use only

Harrison Greenlaw is the Director of Student Orientation and Testing Services and Scott Kaplan is Assistant Director of Student Orientation and Testing Services at the University of South Carolina. 
or a CD-Rom which can provide a stronger multimedia presentation, but which requires additional computer access. There is always detailed information that is difficult to cover during short, time-restrained programs, and the CD can be extremely helpful in those situations. Information that requires considerable detail such as student health resources and financial aid particulars are especially adaptive to the CD concept.

CDs were utilized in 1998 by a handful of institutions of higher education. Examples include:

(a) The University of South Carolina distributed CDs to entering freshmen at summer and fall orientation programs. USC's one-day orientation programs are predominantly academic advising and class registration, and the $\mathrm{CD}$ allows the alma mater, fight song and greetings from the president and the student body president to be made available to students and their parents.

(b) Universities including Marquette University, Iowa State University, Pepperdine University, the University of South Carolina, and California Polytechnic State University distribute interactive CDs to either all admits or to targeted admitted populations such as honors college freshmen and academically elite students.

(c) This fall, housing at the Virginia Polytechnic Institute and State University distributed a CD to each room assigned to an incoming student. Entitled "Alcohol 101," the CD reviewed the Virginia State Law on alcohol regulations and the university's stance on irresponsible drinking. Funding for the "Alcohol 101" CD was provided by Virginia Tech's Vice President of Student Affairs.

(d) Duke University's Auxiliary Services produced a CD which included topics such as textbook and computer purchases, moving into residence halls and other housing issues, parking, ID cards, dining, transportation, local businesses, Duke athletics, the history of Duke University, and sites to see in Durham. Next year, they plan to include more information on other student affairs areas, academics, and campus safety, and it will also be web interactive.

Colleges and universities should consider whether supplementing information on a $\mathrm{CD}$ in addition to the orientation program is a viable option for them. Campuses that historically do not offer an on-campus orientation program can also utilize CDs but they should not replace successful existing programs. In fact, a CD may be one of several worthwhile options to consider for colleges that have the funds, are still in the midst of recruiting students to enroll, have special messages for students prior to their arrival on campus, have a large number of international or out-of-state students, or do not have a summer orientation program 